\title{
MODEL OF LOW-THRUST PULSE DETONATION DEVICE WITH VALVELESS FUEL FEED
}

\author{
D. I. Baklanov, S. V. Golovastov, V. V. Golub, \\ N. V. Semin, and V. V. Volodin
}

\begin{abstract}
A model pulse detonation engine of low thrust is designed. A valveless fuel and oxidant feed was used to fill a combustion chamber. The detonation was formed in the flow of mixed fuel and oxidant. The influence of oxidant on the engine operation mode, the influence of ring obstacles and prechambers on deflagration-to-detonation transition (DDT), and the influence of fuel on engine output parameters were investigated. Air-hydrogen and air-hydrocarbon mixtures were used.
\end{abstract}

\section{INTRODUCTION}

Early attempts to utilize the power obtained from explosions for propulsion applications date back to the late 17 th - early 18 th centuries, and the contributions of Huygens and Allen are noteworthy. In 1729, Allen proposed a jet propelled ship [1] "whose operation is owing to the explosion of gunpowder" in a proper engine placed within a ship. Modern concepts of gaseous and heterogeneous detonation applications for propulsion are described in the review of Roy et al. [2].

In [3], multivalve pulse detonation device (PDD) with separate feeding of fuel and oxidizer is suggested.

At present, only laboratory PDDs operating on gaseous and liquid fuel with air are developed $[2,4-6]$. There are no reliable data on flight tests which is explained with a number of unsolved problems such as imperfect mixing of fuel with air, nonuniform filling of detonation chamber with detonable mixture, low detonability of fuel-air mixture, and high energy expenses on detonation ignition.

These disadvantages can be eliminated by the following ways: preliminary fuel processing aimed at the increase of its detonability [7]; using of forechambers $[4,8]$; cumulation of shock waves (SW) generated by ring discharge [9] or supersonic jets [10]; acceleration of initiating SW by successive electric discharges [11]; and installation of obstacles in detonation chamber [12-14].

The most promising are the valveless PDDs [15]. Fuel and oxidizer supply in such PDDs intermits with necessary frequency due to wave processes in feed

This is an Open Access article distributed under the terms of the Creative Commons Attribution-Noncommercial License 3.0, which permits unrestricted use, distribution, and reproduction in any noncommercial medium, provided the original work is properly cited. 
manifolds. In general, the operation frequency depends on the length of detonation chamber, its diameter, length of feed manifolds, their diameters, feed pressures, types of fuel and oxidizer, and equivalence ratio. A specific feature of a valveless PDD is the fact that ignition and detonation formation occur in the turbulent flow of detonable mixture [16].

In the work of Smirnov et al. [17], a PDD for drilling purposes was presented. The device was fed with a carburated gasoline-air mixture from an automotive engine. The mixture was ignited with an automotive spark plug.

In the paper of Frolov et al. [18], an air-breathing pulse detonation engine demonstrator utilizing liquid fuel was described. It consists of two contours: The first contour serves for periodic detonation initiation in a fuel-air mixture and detonation wave transitioning to the second contour. The detonation wave passing the tube of the second contour is exhausted to the atmosphere through the nozzle, thus producing thrust. Air and fuel mass flow rates in both contours; discharge current in spark plugs, and wave process dynamics were registered during demonstrator operation. A powerful electric discharger, utilized previously for generating primary SW, was replaced by a primary SW generator comprising a relatively low-energy (50-60 J) electric discharger, Schelkin spiral, and tube coil. A second discharger was mounted at the exit of the tube coil and was activated in phase with the primary SW arrival at its position during the cold start. Due to interactions between various wave systems in the tube coil, formed at expansive and compressive surfaces, the total critical energy of the detonation initiation, with two successively triggered dischargers, was decreased to about $100 \mathrm{~J}$, i.e., by an order of magnitude, as compared with the energy $(\sim 1 \mathrm{~kJ})$ required for the direct initiation of the $n$ hexane spray detonation in the straight 28 -millimeter diameter smooth-walled tube, by a single electric discharger. The authors obtained periodic propagation of detonation waves in the combustion chambers of the engine demonstrator with the frequency up to $8 \mathrm{~Hz}$. It should be noted that the authors of Ref. [8] solved the fundamental task of detonating air suspensions of liquid hydrocarbon drops.

The aim of this investigation is design and testing of low-thrust PDD operating on hydrogen or on the mixture of propane-butane with acetylene as the fuel and air as the oxidizer. The PDD does not contain valves for cutting-off fuel and oxidizer supply, and low-power ignition (automotive spark).

\section{EXPERIMENTAL SETUPS}

Valveless fuel and oxidant feed was used to fill a cylindrical combustion chamber (CC) $2500 \mathrm{~mm}$ long and $22 \mathrm{~mm}$ in internal diameter (Fig. 1). The internal diameter was twice larger than the detonation cell size in the stoichiometric 


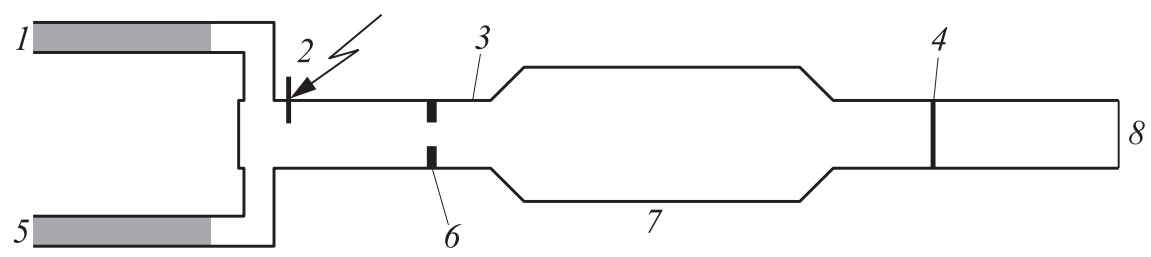

Figure 1 Schematic of pulse detonation engine: 1, 5 - fuel and oxidant feed manifolds; 2 - spark plug; 3 - combustion chamber; 4 - detonation wave; 6 - ring obstacle; 7 - prechamber; and 8 - nozzle

hydrogen-air mixture $(\lambda \sim 10 \mathrm{~mm})$ and a factor of 3.5 larger than the detonation cell size in the stoichiometric acetylene-air mixture $(\lambda \sim 6 \mathrm{~mm})$. The flow velocity in the combustion chamber was $3-6 \mathrm{~m} / \mathrm{s}$ at fuel consumption of $0.5-$ $1 \mathrm{l} / \mathrm{s}$. An electric discharge is used for detonation initiation. The detonation was formed in the flow of mixed fuel and oxidant.

The influence of oxidant on the operating mode of devices, the influence of ring obstacles and prechambers on DDT, and the influence of fuel on output parameters of the devices were investigated.

At flow velocity of $2 \mathrm{~m} / \mathrm{s}$, the predetonation distance in the stoichiometric hydrogen-air mixture was less than 14 tube diameters. The presence of ring obstacles (blockage ratio, $\mathrm{BR}=A_{\text {obstacle }} / A_{\text {channel }}=0.75-0.94$ ) and prechambers (expansion ratio, $\left.\mathrm{ER}=A_{\text {chamber }} / A_{\text {channel }}=2.56\right)$ in the combustion chamber led to reduction of the predetonation distance in the stoichiometric hydrogenair mixture more than by a factor of 2 (from more than 90 tube diameters to 45$)$. The use of inhibited acetylene $\left(90 \% \mathrm{C}_{2} \mathrm{H}_{2}+10 \%\right.$ propane-butane) as fuel allowed reducing the predetonation distance to 30 tube diameters. The operation frequency of detonation devices was $1 \mathrm{~Hz}$ (for hydrogen) and $5 \mathrm{~Hz}$ (for acetylene).

Acetylene is known to be capable of decomposing with the formation of hydrogen and carbon or methane accompanied with energy release and possible detonation formation. So, acetylene containing fuel should be tested in terms of explosion safety. Acetylene decomposition is a complex chain-branching reaction. A lot of chemical mechanisms were suggested in the literature, e.g., [19-21]. All of them include reactions with $\mathrm{H}$ (atomic hydrogen) radicals. The presence of $\mathrm{H}$ radicals causes glow that may be detected with camera or photodetector. Thus, one can detect acetylene decomposition based on the presence of glow in the measuring section. Test experiments with measuring glow intensity soot yield indicated that the approach applied was sufficiently accurate for the purposes of the study.

The experimental investigations were performed in a cylindrical shock tube of an overall length of $1617 \mathrm{~mm}$ and inner diameter of $22 \mathrm{~mm}$ (Fig. 2). The 


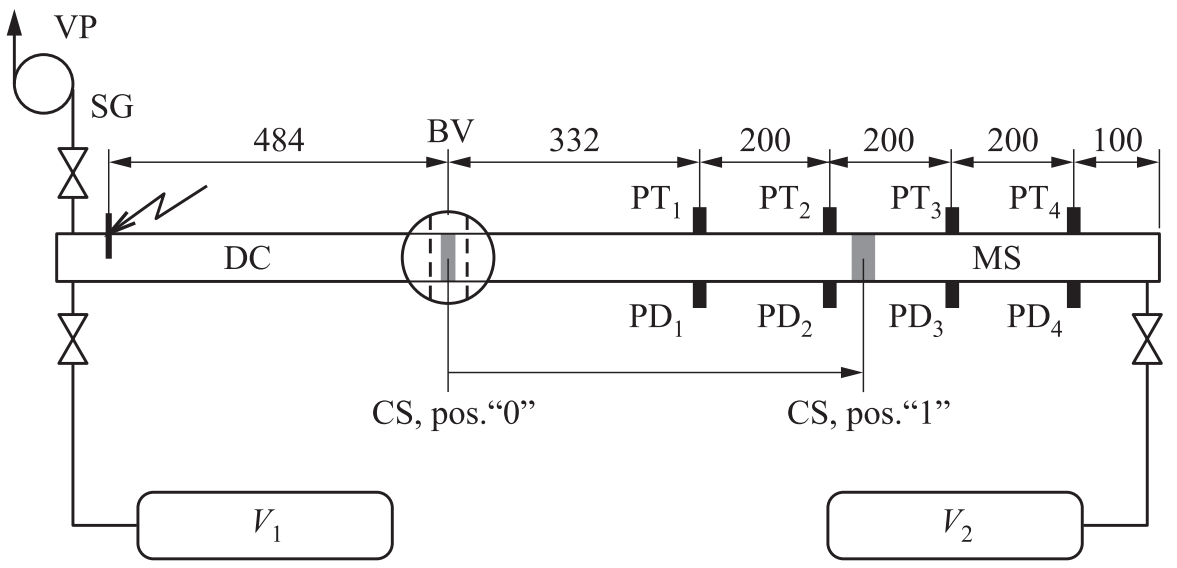

Figure 2 Schematic of experimental setup: DC - detonation chamber; MS - measuring section; $\mathrm{BV}$ - ball valve; $\mathrm{VP}$ - vacuum pump; $\mathrm{SG}$ - spark gap; $\mathrm{PT}_{1}-\mathrm{PT}_{4}$ PCB 113A piezoelectric pressure transducers; $\mathrm{PD}_{1}-\mathrm{PD}_{4}-\mathrm{PD}-256$ photodiodes; $\mathrm{CS}-$ contact surface; pos. "0" and pos. "1" - initial and final positions of the contact surface; $\mathrm{V}_{1}$ - cylinder with stoichiometric acetylene-oxygen mixture; $\mathrm{V}_{2}$ - cylinder with acetylene-inhibitor mixture. Dimensions are in millimeters

shock tube consisted of a detonation chamber (DC) $585 \mathrm{~mm}$ long and a measuring section (MS) $1032 \mathrm{~mm}$ long separated by a ball valve (BV). The recording equipment included PCB 113A piezoelectric pressure transducers (PT) and FD256 photodiodes (PD). The spacing between the tranducers was $200 \mathrm{~mm}$, and the distance between the first transducer and spark gap (SG) was $816 \mathrm{~mm}$.

The DC was filled with a stoichiometric acetylene--oxygen mixture to a pressure of $1 \mathrm{~atm}$, and the MS - with an acetylene-inhibitor mixture to the same pressure with closed $\mathrm{BC}$. The $\mathrm{DC}$ and $\mathrm{MS}$ were preevacuated to a pressure of $0.004 \mathrm{~atm}$. The test mixture was composed by partial pressures of the components with an error of $0.5 \%$. The mixture was kept for at least $42 \mathrm{~h}$ in a 3 -liter vessel at a pressure of $2 \mathrm{~atm}$. After filling, the ball valve was open, the acetyleneoxygen mixture was ignited by a spark gap, and detonation was formed. The predetonation distance was less than $20 \mathrm{~mm}$, which is much less than the DC length. A detonation wave formed in the acetylene-oxygen mixture passed the contact surface (CS) (position "0") from left to right and transformed to a shock wave in the test mixture.

The length of MS was selected such that the CS would reach pressure transducers $\mathrm{PT}_{1}$ and $\mathrm{PT}_{2}$ but would not reach the transducers $\mathrm{PT}_{3}$ and $\mathrm{PT}_{4}$. The CS stopped at an instant of its interaction with a reflected SW behind which the gas is quiescent (position "1" in Fig. 2). Therefore, the last pair of pressure transducers could register only the glow of decomposing acetylene. 


\section{RESULTS}

\subsection{Acetylene Phlegmatization}

Figure 3 shows measured time histories of shock-wave processes in the mixtures of acetylene with inhibitor. When the inhibitor content in acetylene is $6 \%$ (vol.) and less (Fig. 3a), a wave of acetylene exothermal decomposition (DW) forms in MS. Pressure transducers $\mathrm{PT}_{1}-\mathrm{PT}_{4}$ register the incident (SW) and reflected (RSW) shock waves. The $\mathrm{PD}_{1}$ photodiode registers the arrival of contact surface (CS) and the glow of detonation products of acetylene at the instant of reflected SW transmission. The $\mathrm{PD}_{3}$ and $\mathrm{PD}_{4}$ photodiodes register the intense glow of the acetylene decomposition wave behind the reflected shock wave. As is seen from Fig. $3 a$, the decomposition wave DW propagates in the wake of the reflected SW.

No spontaneous decomposition of acetylene occurs when the inhibitor concentration is $7 \%$ (vol.) and higher (Fig. $3 b$ ). The PD1 and PD2 photodiodes register the arrival of $\mathrm{CS}$ and the glow of detonation products of acetylene at the instant of RSW transmission. However, $\mathrm{PD}_{3}$ and $\mathrm{PD}_{4}$ photodiodes register no glow of gas during $20 \mathrm{~ms}$. This is indicative of the absence of DW in acetylene.

Table 1 gives the measured parameters (except for temperature) of the test mixture behind the incident and reflected shock waves at a position of $\mathrm{PT}_{4}$. One

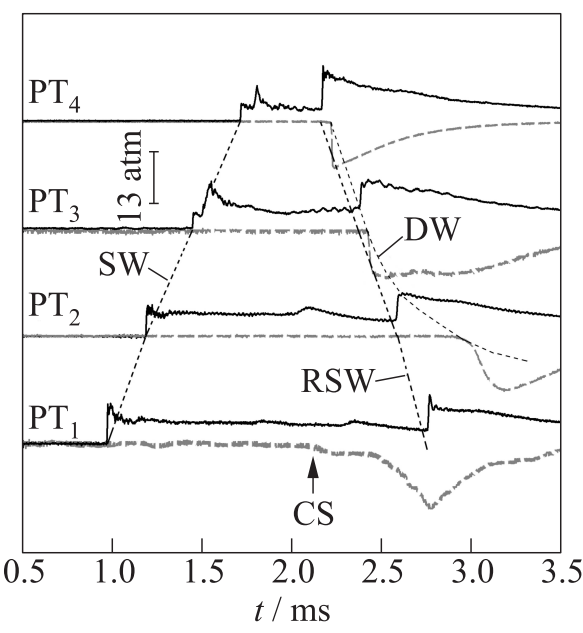

(a)

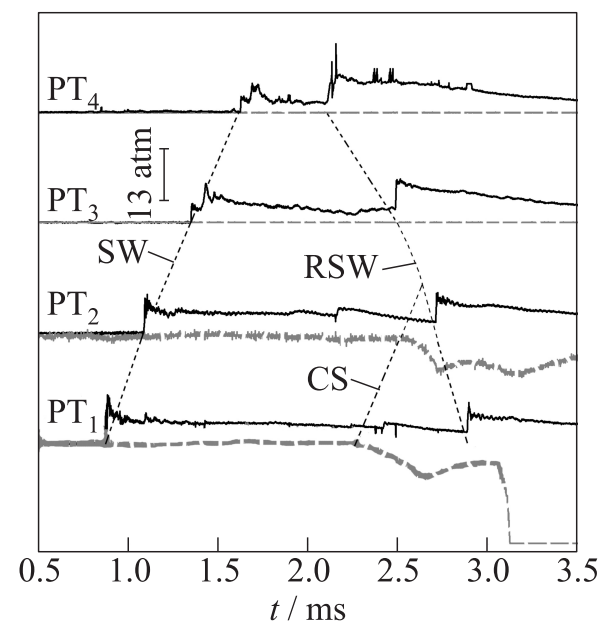

(b)

Figure 3 Measured time histories of pressure (solid curves), glow (dash curves), and trajectories of waves and contact surface (dotted curves) in the presence of inhibitor: (a) inhibitor concentration of $6 \%$ (vol.); and (b) inhibitor concentration of $7 \%$ (vol.) 
Table 1 Parameters of unreacted gas behind the incident and reflected shock waves at the position of $\mathrm{PT}_{4}: C_{\mathrm{inh}}$ - concentration of inhibitor in acetylene; $\mathrm{M}_{\mathrm{SW}}-\mathrm{Mach}$ number of incident SW; $P_{\mathrm{SW}}$ - pressure at the SW front; $T_{\mathrm{SW}}$ - temperature at the $\mathrm{SW}$ front; $P_{\mathrm{RSW}}$ - pressure in the RSW front; and $T_{\mathrm{RSW}}$ - temperature in the RSW front

\begin{tabular}{ccccccc}
\hline $\begin{array}{c}C_{\text {inh }}, \\
\%\end{array}$ & $\mathrm{M}_{\mathrm{SW}}$ & $P_{\mathrm{SW}}$, atm & $T_{\mathrm{SW}}, \mathrm{K}$ & $\begin{array}{c}P_{\mathrm{RSW}}, \\
\mathrm{atm}\end{array}$ & $T_{\mathrm{RSW}}, \mathrm{K}$ & \\
\hline 0 & $2.18 \pm 0.12$ & $5.4 \pm 0.6$ & $530 \pm 29$ & $11.8 \pm 3.2$ & $819 \pm 66$ & \\
2.5 & $2.44 \pm 0.05$ & $6.8 \pm 0.3$ & $598 \pm 18$ & $16.1 \pm 4.5$ & $973 \pm 29$ & Decomposition \\
5 & $2.34 \pm 0.09$ & $6.2 \pm 0.5$ & $570 \pm 23$ & $14.2 \pm 2.2$ & $911 \pm 51$ & \\
6 & $2.14 \pm 0.07$ & $5.2 \pm 0.4$ & $551 \pm 18$ & $10.7 \pm 2.3$ & $796 \pm 53$ & \\
\hline 7 & $2.06 \pm 0.06$ & $4.8 \pm 0.3$ & $532 \pm 21$ & $9.5 \pm 1.9$ & $752 \pm 48$ & \\
10 & $2.24 \pm 0.09$ & $5.7 \pm 0.4$ & $540 \pm 19$ & $12.2 \pm 0.7$ & $842 \pm 52$ & No decomposition \\
25 & 2.02 & 4.6 & 481 & 8.1 & 709 & \\
\hline
\end{tabular}

can see that the pressure behind the RSW increases as high as 13 to $20 \mathrm{~atm}$, and the temperature attains the values as high as 800 to $1000 \mathrm{~K}$. In all cases, except for the case of inhibitor concentration of $25 \%$ (vol.), the conditions of the acetylene-inhibitor mixture behind the reflected and incident SWs were identical. Therefore, one can belive that the obtained results are correct.

\subsection{Testing of Valveless Pulse Detonation Device}

Three different configurations of the CC shown in Fig. 4 were used to study the influence of the CC shape on detonation parameters. In different experiments, one or two annular ring obstacles with orifice diameter ranging from 5 to $10 \mathrm{~mm}$ (blockage ratio $0.75-0.94$ ) and/or precombustion chamber (tube section $620 \mathrm{~mm}$ long, Fig. $4 b$ ) were installed in the CC. A series of experiments in the CC of variable diameter (Fig. 4c) was also carried out. The arrangement of annular obstacles along the tube was varied to find the most advantageous arrangement.

The use of annular obstacles and precombustion chambers made it possible to reduce the predetonation distance to less than hundred tube diameters. It is evident from Fig. 5 that the presence of a single annular obstacle in the tube of constant diameter causes reflection of SW, formation of hot jet of combustion products, and detonation initiation. The classical initiation mechanism of detonation with SW reflection followed by diffraction of the formed detonation in the opening is not applied in this case because of the small chamber diameter ( $\sim 2$ detonation cells) and very small orifice diameter in the obstacle $(\sim 1 / 3$ of detonation cell). This process reduces the predetonation distance by a factor 


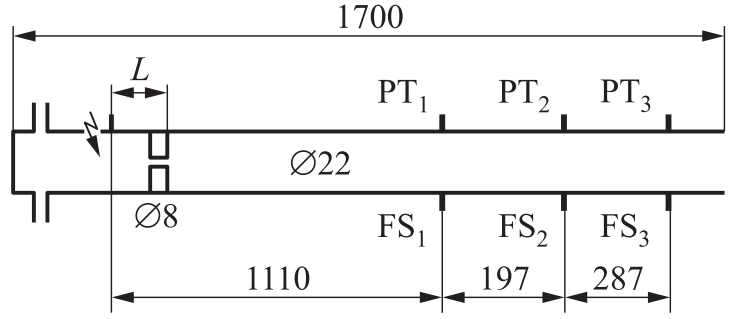

(a)

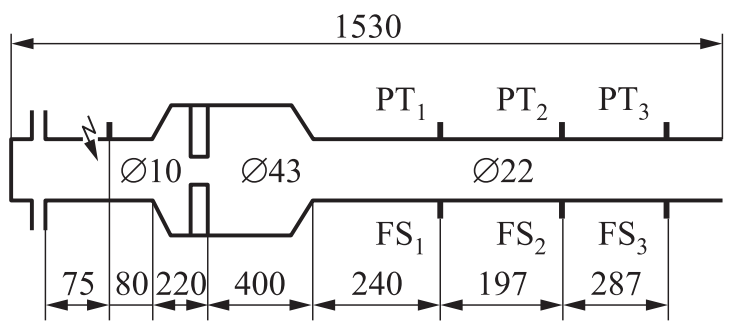

(b)

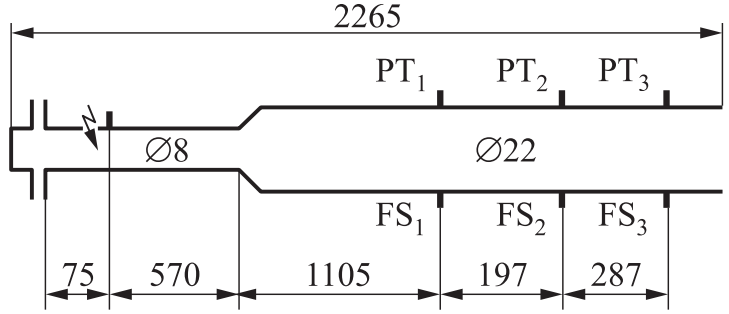

(c)

Figure 4 Combustion chambers tested in the experiments: $(a)$ with annular obstacles $(\mathrm{AO}) ;(b)$ with precombustion chamber and $\mathrm{AO}$; and $(c)$ with variable cross-section area. Dimensions are in millimeters

of 1.5. Decreasing orifice diameter and increasing the distance between the obstacle and the spark lead to further reduction of the predetonation distance that confirms the jet mechanism of detonation initiation.

In Fig. 6, the predetonation distances in the $\mathrm{CC}$ with two annular obstacles are presented. In the tube of constant cross section, a strong dependence of the predetonation distance on the position of obstacles is observed: two annular obstacles with orifice diameter $8 \mathrm{~mm}$, located at a distance of $205 \mathrm{~mm}$ (9.3 tube diameters) and $610 \mathrm{~mm}$ (27.7 tube diameters) from the spark plug reduce the predetonation distance by $20 \%$ as compared with the smooth tube. If the ob- 


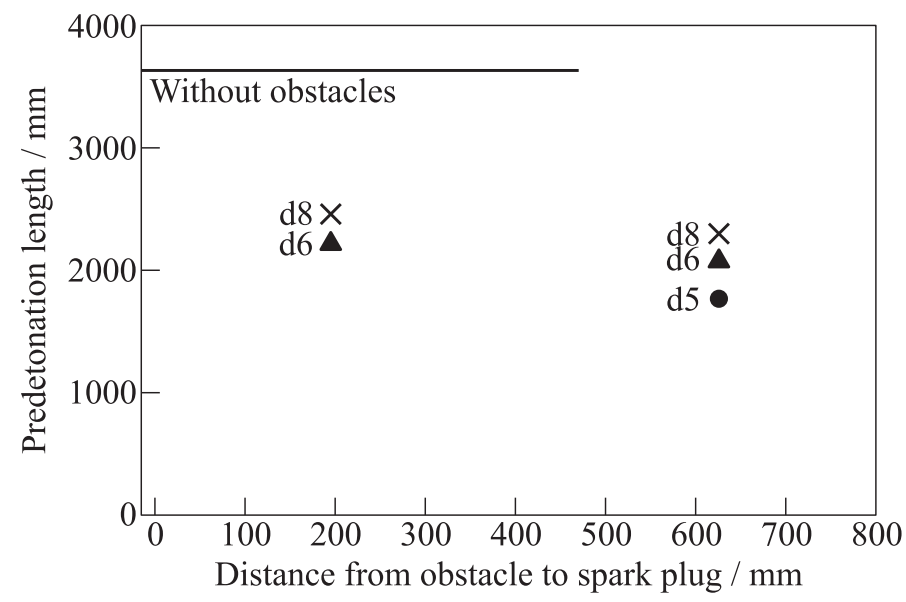

Figure 5 Predetonation distance as a function of the position of annular obstacle in $\mathrm{CC}$

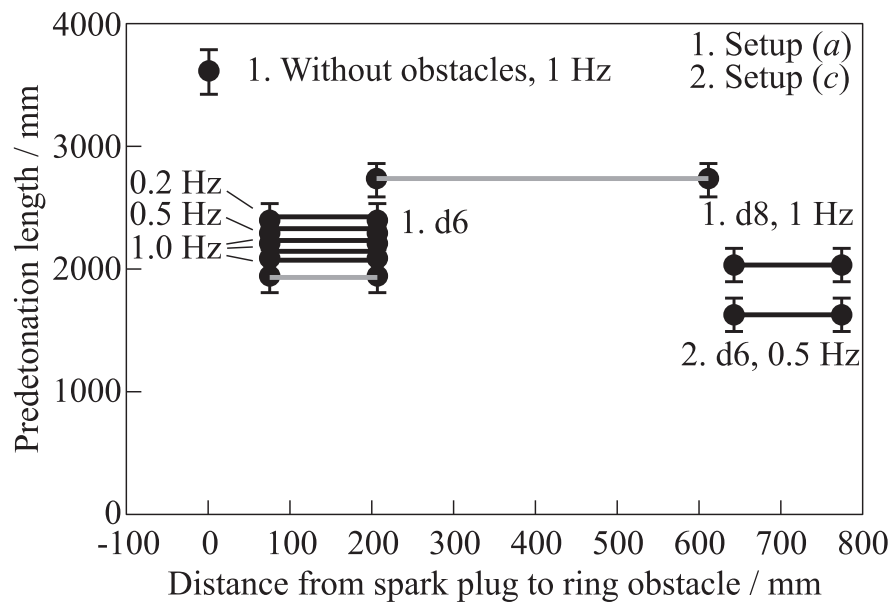

Figure 6 Predetonation distance as a function of the position of annular obstacles for $\mathrm{CC}$ with two annular obstacles. Lines connect the points corresponding to experimental data, obtained with identical CC configurations with a different distance between spark and obstacle

stacles are located at a distance of $75 \mathrm{~mm}$ (3.4 tube diameters) from each other and $205 \mathrm{~mm}$ (9.3 tube diameters) from the spark plug, the reduction of the predetonation distance is $40 \%$. Both increase in orifice diameter and increase in the operation frequency (and correspondingly the flow velocity in CC) from 0.2 


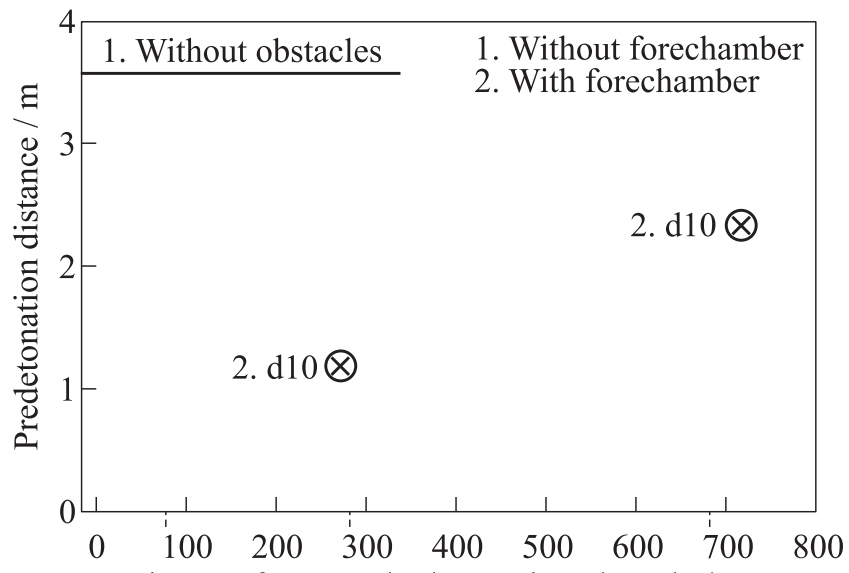

Distance from spark plug to ring obstacle $/ \mathrm{mm}$

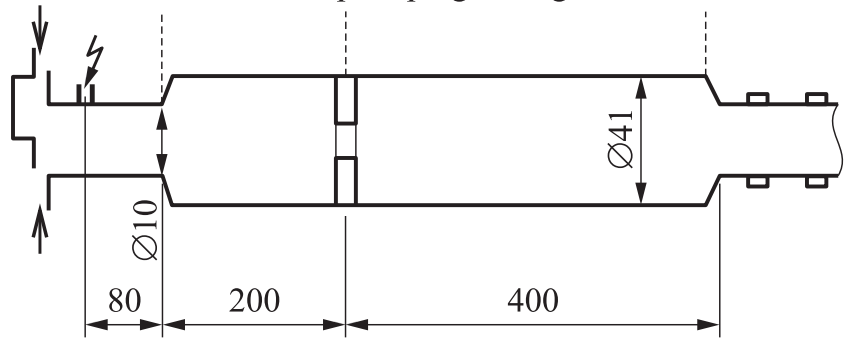

Figure 7 Predetonation distance as a function of the position of annular obstacles in CC with the precombustion chamber and annular obstacle. Dimensions are in millimeters

to $1 \mathrm{~Hz}$ contribute to further reduction of the predetonation distance. Experiments on the setup with variable cross section (see Fig. 4c) showed that this configuration of $\mathrm{CC}$ contributes to the reduction of the predetonation distance by a factor of 2 in comparison with the tube of constant cross section without obstacles. Clearly, the effect of predetonator takes place when fast combustion or detonation in the small-diameter tube is transitioned to the tube of larger diameter.

The availability of the precombustion chamber with a length of $600 \mathrm{~mm}$ at a distance of $80 \mathrm{~mm}$ from the spark plug with the annular obstacle inside it (see Fig. $4 b$ ) reduces the predetonation distance by a factor of 3 in comparison with the smooth tube. Moreover, this result is sufficiently reproducible and the discrepancy is comparable with measurement error (5\%). Significant dependence on the position of the annular obstacle was observed (Fig. 7): increasing the distance from the obstacle to the spark plug reduces the predetonation distance by a factor less than $\sim 1.5$. The same effect was obtained with the precom- 
bustion chamber of smaller length with the orifice of smaller diameter. When comparing these results with the data of other researchers obtained for the initially quiescent mixture, one comes to a conclusion that they agree with each other qualitatively.

In the experiments, acetylene inhibited by propane-butane mixture $\left(90 \% \mathrm{C}_{2} \mathrm{H}_{2}+10 \%\right.$ propane-butane) was also used as fuel. This led to the decrease of the predetonation distance to 30 tube diameters which can be explained by higher detonability of acetylene-air mixture.

In pulse detonation mode, the setup was operated with two oxidizers, oxygen and air. At frequencies above $0.5 \mathrm{~Hz}$, the use of oxygen as the oxidizer was prohibited due to excessive heating of $\mathrm{CC}$ resulting in transition of cyclic detonation mode to the intermittent combustion mode of setup operation. Therefore, at frequencies above $0.5 \mathrm{~Hz}$, air was used as an oxidizer.

Thrust measurements were also made for estimating the propulsive efficiency of the detonation process. Thrust measurements were conducted using the installation of Fig. $4 c$ with hydrogen and inhibited acetylene as fuels. For both types of fuel, the maximum measured thrust value was identical and equal to $50 \mathrm{~g}$ at a frequency of $1 \mathrm{~Hz}$.

\section{CONCLUDING REMARKS}

Three PDD combustion chamber designs were investigated, all operating on a stoichiometric hydrogen-air mixture. The use of precombustion chamber with annular obstacles was shown to reduce the DDT length.

Acetylene-containing mixtures were also considered as a possible PDD fuel. Acetylene was inhibited by a gas (propane-butane) that is a fuel per se. The minimal concentration of inhibitor has been experimentally determined, at which no spontaneous decomposition of acetylene occurred behind RSW. This minimal concentration was $7 \%$ (vol.). The data obtained can be employed for storage and transportation of acetylene in undissolved state.

The regimes of cyclic detonation initiation in acetylene and hydrogen mixtures with oxygen and air were obtained experimentally. The thrust created by detonations was measured. The influence of tube geometry on the formation of detonation was evaluated.

\section{ACKNOWLEDGMENTS}

This work was supported financially by the Russian Academy of Sciences Presidium Programs (P-9 and DE-1) and performed under the contract to the International Science and Technology Center (ISTC), Moscow. 


\section{REFERENCES}

1. Lyle Cummins JrC. 1976. Internal fire. Lake Oswego, Oregon: Carnot Press.

2. Roy, G.D., S.M. Frolov, A. A. Borisov, and D. W. Netzer. 2004. Pulse detonation propulsion: Challenges, current status, and future perspective. Prog. Energy Combust. Sci. 30(6):545-672.

3. Hunter. L. G., G. Louis, and D. D. Winfree. 1996. U.S. Patent No. 5,557,926. Priority 24.09.96.

4. Brophy, C. M., D.W. Netzer, J. Sinibaldi, and R. Johnson. 2001. Detonation of JP-10 aerosol for pulse detonation applications. In: High-speed deflagration and detonation: Fundamentals and control. Eds. G. Roy, S. Frolov, D. Netzer, and A. Borisov. Moscow: ELEX-KM Publ. 207-22.

5. Baklanov, D. I., L. G. Gvozdeva, and N. B. Sherbak. 2001. Pulsed detonation combustion chamber for PDE. In: High-speed deflagration and detonation: Fundamentals and control. Eds. G. Roy, S. Frolov, D. Netzer, and A. Borisov. Moscow: ELEX-KM Publ. 239-50.

6. Shauer, F., J. Stutrud, R. Bradley, V. Katta, and J. Hoke. 2003. Detonation studies and performance results for a research pulse detonation engine. In: Confined detonations and pulse detonation engines. Eds. G. Roy, S. Frolov, R. Santoro, and S. Tsyganov. Moscow: TORUS PRESS. 287-302.

7. Levin, V.A., J. N. Nechaev, and A.I. Tarasov. 2001. A new approach to organizing operation cycles in pulsed detonation engines. In: High-speed deflagration and detonation: Fundamentals and control. Eds. G. Roy, S. Frolov, D. Netzer, and A. Borisov. Moscow: ELEX-KM Publ. 223-38.

8. Murray, S.B., P.A. Thibault, F. Zhang, D. Bjerketvedt, A. Sulmistras, G. O. Thomas, A. Jenssen, and I. O. Moen. 2001. The role of energy distribution on the transmissiun of detonation. In: High-speed deflagration and detonation: Fundamentals and control. Eds. G. Roy, S. Frolov, D. Netzer, and A. Borisov. Moscow: ELEX-KM Publ 139-62.

9. Korobeinikov, V.P., V. V. Markov, I. V. Semenov, P. D. Pedrow, and S. Wojcicki. 2001. Electrochemical pulse detonation engine. In: High-speed deflagration and detonation: Fundamentals and control. Eds. G. Roy, S. Frolov, D. Netzer, and A. Borisov. Moscow: ELEX-KM Publ. 289-302.

10. Achasov, O. V., and O. G. Penyazkov. 2001. Some gasdynamic methods for control of detonation initiation and propagation. In: High-speed deflagration and detonation: Fundamentals and control. Eds. G. Roy, S. Frolov, D. Netzer, and A. Borisov. Moscow: ELEX-KM Publ. 31-44.

11. Frolov, S. M., V. Ya. Basevich, V.S. Aksenov, and S. A. Polichov. 2002. Initiation of spray detonation by successive triggering of electric discharges. In: Advances of confined detonations. Eds. G. Roy, S. Frolov, R. Santoro, and S. Tsyganov. Moscow: TORUS PRESS. 150-57.

12. Smirnov, N. N., V.F. Nikitin, M. V. Tyurnikov, A.P. Boichenko, J. C. Legros, and V.M. Shevtsova. 2001. Control of detonation onset in combustible gases. In: High-speed deflagration and detonation: Fundamentals and control. Eds. G. Roy, S. Frolov, D. Netzer, and A. Borisov. Moscow: ELEX-KM Publ. 3-30. 
13. Higgins, A. J., P. Pinard, A.C. Yoshinaka, and J.H.S. Lee. 2001. Sensitization of fuel-air mixtures for deflagration-to-detonation transition. In: High-speed deflagration and detonation: Fundamentals and control. Eds. G. Roy, S. Frolov, D. Netzer, and A. Borisov. Moscow: ELEX-KM Publ. 45-62.

14. Semenov, I., S. Frolov, V. Markov, and P. Utkin. 2006. Shock-to-detonation transition in tubes with shaped obstacles. In: Pulsed and continuous detonations. Eds. G. Roy, S. Frolov, and J. Sinibaldi. Moscow: TORUS PRESS. 159-69.

15. Baklanov, D. I., D. G. Zhimerin, Ju. N. Kiselev, E. L. Mironov, and V. A. Popov. 1976. On some technical aspects of detonation regime of combustiom using. Combust. Explosion Shock Waves 12(1):47-52.

16. Baklanov, D. I., S. V. Golovastov, V. V. Golub, and V. V. Volodin. 2004. Detonation formation in moving detonable mixture flow. In: Application of detonation to propulsion. Eds. G. Roy, S. Frolov, and J. Shepherd. Moscow: TORUS PRESS. $225-31$.

17. Smirnov, N. N., V.F. Nikitin, A.P. Boichenko, M. V. Tyurnikov, and V. V. Baskakov. 1999. Control of deflagration to detonation transition in gases and its application to pulsed detonation devices. In: Gaseous and heterogeneous detonations: Science to applications. Eds. G. Roy, S. Frolov, K. Kailasanath, and N. Smirnov. Moscow: ENAS Publ. 65-94.

18. Frolov, S. M., V.S. Aksenov, and V. Ya. Basevich. 2005. Air-breathing liquidfueled pulse detonation engine demonstrator. Doklady Physical Chemistry 402(part 4):93-95.

19. Tanzawa, T., and W. C. Gardiner. 1980. Reaction mechanism of the homogeneous thermal decomposition of acetylene. J. Phys. Chem. 84(3):236-39.

20. Clary, D., M. Frenklach, W. Gardiner, and St. Stein. 1984. Detailed kinetic modeling of soot formation in shock-tube pyrolysis of acetylene. 20th Symposium (International) on Combustion Proceedings. The Combustion Institute. 887-901.

21. Krestinin, A. V. 1994. About mechanism of soot-formation from acetylene. Chem. Phys. Rep. 13(1):121-31. 